\title{
Physiotherapists' knowledge of pain: A cross-sectional correlational study of members of the South African Sports and Orthopaedic Manipulative Special Interest Groups
}

\author{
N Clenzos, ${ }^{1}$ MPhil; N Naidoo, ${ }^{2} \mathrm{MSc} ;$ R Parker, ${ }^{2} \mathrm{PhD}$ \\ ${ }^{1}$ SAS Physiotherapy, Stellenbosch Academy of Sport, Stellenbosch, South Africa \\ ${ }^{2}$ Division of Physiotherapy, Department of Health and Rehabilitation Sciences, University of Cape Town, Cape Town, South Africa \\ Corresponding author: N Clenzos (nadiaclenzos@yahoo.com)
}

Background. Pain is the most common complaint for which patients seek the help of a physiotherapist. Furthermore, pain has been identified as the fifth vital sign, indicating the attention with which physiotherapists should be assessing pain. Previous studies have found deficits in pain knowledge among healthcare providers. Poor knowledge about pain is recognised to lead to poor assessment ability, and subsequently, to poor pain management.

Objective. To investigate the pain knowledge of sports and orthopaedic manipulative physiotherapists in South Africa (SA).

Methods. Data were collected online by means of a demographic questionnaire and Unruh's Revised Pain Knowledge and Attitudes Questionnaire (RPKAQ). Participants were members of the Sports Physiotherapy Group and Orthopaedic Manipulative Physiotherapy Group of the South African Society of Physiotherapy.

Results. The mean score for the RPKAQ was $65.5 \%$ (standard deviation (SD) \pm 8.6 ). Only $14.45 \%$ of the physiotherapists scored $\geq 75 \%$. Lowest scores were obtained for the 'assessment and measurement of pain' ( $47.6 \%$; $\mathrm{SD} \pm 15.6)$ and 'developmental changes in pain perception' (58.7\%; SD \pm 20.8 ) sections of the RPKAQ, while the highest mean score was obtained for the 'physiological basis of pain' section (76.8\%; $\mathrm{SD} \pm 14.6$ ). Gender, ethnicity (defined by home language), academic training and clinical experience did not contribute significantly to overall pain knowledge.

Conclusion. There is an inadequate level of pain knowledge among members of the sports and orthopaedic manipulative physiotherapy groups in SA, particularly in the areas of the assessment and measurement of pain, and developmental changes in pain perception.

S Afr J SM 2013;25(4):95-100. DOI:10.7196/SAJSM.502

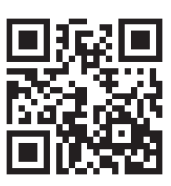

Pain is defined by the International Association for the Study of Pain (IASP) as '... an unpleasant sensory and emotional experience associated with actual or potential tissue damage, or described in terms of such damage; pain is always subjective ... '? ${ }^{[1]}$ Pain is recognised as the most common complaint for which individuals seek the help of a physiotherapist; ${ }^{[2]}$ however, the most commonly cited reasons for mismanagement of pain are healthcare practitioners' negative attitudes and lack of knowledge about pain. ${ }^{[3]}$

Pain has been identified as the fifth vital sign, ${ }^{[4,5]}$ indicating the attention with which physiotherapists should be assessing pain. Vital signs are measures used to assess basic body functions. The four primary functions include temperature, blood pressure, heart rate and respiratory rate. ${ }^{[5]}$ Pain as the fifth vital sign was initially promoted by the American Pain Society to elevate awareness of pain treatment among healthcare professionals. Vital signs are critical; therefore, if pain was to be assessed as seriously as other vital signs, this may lead to an improved chance of adequate and optimal treatment. ${ }^{[6]}$ Physiotherapists are accepted and involved members of the pain-management team ${ }^{[7]}$ concerned with identifying possible causes of pain. All physiotherapists registered with the Health Professions Council of South Africa are considered first-line practitioners. ${ }^{[8]}$
Understanding the science behind nociceptive and pain neurophysiology during the clinical assessment of patients with musculoskeletal pain is crucial in determining appropriate treatment parameters ${ }^{[9]}$ Physiotherapists' clinical reasoning of pain may influence reasoning associated with other aspects of clinical practice, such as the planning of physical examinations, treatment and prognostication. ${ }^{[10]}$ Further, central sensitisation plays an important role in the pathophysiology of numerous musculoskeletal pain disorders, yet it remains unclear how physiotherapists can recognise this condition..$^{[9]}$

There is a paucity of evidence relating to pain knowledge and assessment ability among healthcare professionals. The implications for physiotherapy practice are that such poor knowledge is recognised to lead to poor assessment ability, and subsequently, to poor pain management. ${ }^{[4]}$ A greater understanding of pain mechanisms may enable more effective treatment and management of clinical presentations of pain. ${ }^{[10]}$ In South Africa (SA), there is a lack of research on healthcare professionals' knowledge of pain, particularly such knowledge among physiotherapists.

The principle aim of this study was to provide baseline descriptive information regarding pain knowledge among SA sports and orthopaedic manipulative physiotherapists, particularly those treating athletes, and to explore factors which contribute to level of knowledge. 
a-if

\begin{tabular}{ll} 
& de \\
\hline There is a predictable relationship between the extent of an injury and a person's perception of pain & 0.61
\end{tabular}

$\begin{array}{ll}\text { Pain is a physiological sensation } & 0.62\end{array}$

$\begin{array}{ll}\text { The sensation of pain varies from individual to individual } & 0.62\end{array}$

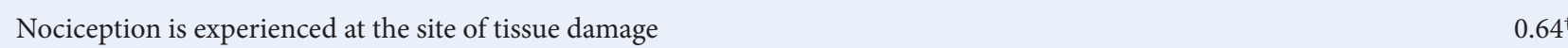

$\begin{array}{lr}\text { The physiological basis of pain is well understood } & 0.62\end{array}$

$\begin{array}{ll}\text { The intensity of pain is its most important quality } & 0.62\end{array}$

Two people with exactly the same physical condition or trauma will have similar experiences of pain 0.62

$\begin{array}{lr}\text { Pain is a subjective experience } & 0.62\end{array}$

$\begin{array}{ll}\text { The duration of pain is similar for individuals with the same pain condition } & 0.61\end{array}$

$\begin{array}{ll}\text { Unrelieved pain contributes to the onset of chronic pain } & 0.62\end{array}$

$\begin{array}{lr}\text { Chronic pain always has an underlying psychological cause } & 0.62\end{array}$

$\begin{array}{ll}\text { A person's statement about pain should always be accepted at face value } & 0.62\end{array}$

If there is no organic basis for the pain, then the pain is psychological $\quad 0.60$

$\begin{array}{lr}\text { Psychologically caused pain can hurt as much as organically caused pain } & 0.62\end{array}$

$\begin{array}{ll}\text { A person receiving compensation is less likely to recover from pain } & 0.62\end{array}$

$\begin{array}{lr}\text { Chronic pain frequently leads to depression } & 0.62\end{array}$

It is common for someone with chronic pain to feel little control over the pain 0.62

Improving an individual's coping skills is more important than determining the extent to which there may be a psychological 0.62 cause of the pain

Pain due to a physiological cause and pain due to a psychological cause can occur simultaneously 0.62

$\begin{array}{ll}\text { People with chronic pain can continue to live productive lives } & 0.62\end{array}$

A person may have severe pain, but appear calm and rational at the same time 0.62

$\begin{array}{ll}\text { Learning to tolerate pain builds character } & 0.61\end{array}$

Relief of pain is often more important to the person than treatment of the underlying condition 0.62

$\begin{array}{ll}\text { Deliberate faking of pain is rare among people with pain } & 0.62\end{array}$

$\begin{array}{lr}\text { A child who is playing after surgery may have pain } & 0.62\end{array}$

$\begin{array}{ll}\text { Children experience less pain than adults } & 0.59\end{array}$

$\begin{array}{ll}\text { Due to the immaturity of the nervous system, newborns have little sensitivity to pain } & 0.58\end{array}$

$\begin{array}{ll}\text { Children have a higher tolerance for pain than adults } & 0.59\end{array}$

$\begin{array}{lc}\text { Children can have severe headaches or migraines } & 0.63^{\dagger}\end{array}$

If children are given medication for pain, they are more likely to think that drugs will solve their problems later in life $\quad 0.61$

$\begin{array}{ll}\text { A premature infant is able to feel pain } & 0.60\end{array}$

Children who have recurrent abdominal pain are probably seeking attention or trying to escape responsibilities 0.61

$\begin{array}{ll}\text { Elderly people tolerate more pain } & 0.62\end{array}$

It is impossible to measure pain in an individual who is unable to communicate about pain 0.61

$\begin{array}{ll}\text { Behavioural measures of pain are reliable measures of short, sharp pain } & 0.62\end{array}$

$\begin{array}{ll}\text { Self-report is the most meaningful measure of pain } & 0.62\end{array}$

$\begin{array}{lr}\text { Children remember pain } & 0.61\end{array}$

$\begin{array}{ll}\text { A person, who is sleeping, may have significant pain } & 0.62\end{array}$

Blood pressure, heart rate, respiration and sweating are good measures of postoperative pain 0.62

Increasing levels of endogenous opioids can help to determine if chronic pain is due to a cause (NB: endogenous opioids 0.62 are produced by the body)

Pain can be reliably measured on a variety of numeric scales
0.62

continued... 
Table 1 (continued). RPKAQ reliability ${ }^{\star}$

\begin{tabular}{ll}
\hline & $\begin{array}{c}\boldsymbol{\alpha} \text { - if } \\
\text { deleted }\end{array}$ \\
\hline Behavioural measures of pain are reliable indicators of chronic pain & 0.61 \\
Asking the person 'how do you feel?' is usually the best way to measure pain & 0.62 \\
Frequent measurement of acute pain may make the pain worse & 0.61 \\
Being engaged in meaningful activity may reduce a person's perception of pain & 0.62 \\
Cognitive/behavioural methods of pain relief are more effective than pharmacological methods & 0.61 \\
Relaxation is an effective method of pain relief for mild to moderate levels of pain & $0.63^{\dagger}$ \\
Reinforcement of coping with pain is an important treatment intervention & 0.62 \\
A spouse, parents or other family members may exacerbate non-coping behaviours & 0.62 \\
Cognitive/behavioural methods have more effect on reducing mild pain than pain which is moderate or severe & $0.63^{\dagger}$ \\
Progressive relaxation (tension with relaxation) may cause more pain & 0.62 \\
It is preferable to use cognitive/behavioural methods rather than pharmacological treatments for pain relief & 0.62 \\
Changing a person’s patterns of thought regarding pain may improve coping skills. & 0.62 \\
Cognitive/behavioural methods may have more impact on improving coping than on reducing the intensity of pain. & 0.61 \\
RPKAQ = Revised Pain Knowledge and Attitudes Questionnaire. & \\
*Summary for scale: Cronbach's $=0.62$. & 'Increase in -value.
\end{tabular}

\section{Methods}

\section{Ethical approval}

The study was performed in accordance with the principles of the Declaration of Helsinki (Seoul version, 2008). The study was approved by the Human Research Ethics Committee of the Faculty of Health Sciences, University of Cape Town (FHS HREC ref. 312/2011).

\section{Participants}

Participants were recruited by electronic correspondence using the South African Society of Physiotherapy Special Interest Group database. Members of the Sports Physiotherapy Group (SPG) and/ or Orthopaedic Manipulative Physiotherapy Group (OMPTG) of the South African Society of Physiotherapy ( $N=1562)$ were invited to participate. Using the pain knowledge scores obtained by SA physiotherapy students in a previous study $(68.9 \%)^{[4]}$ with a $4 \%$ precision interval (score range $63.9-73.9 \%$ ), a sample size of 272 ( $17.4 \%$ response rate) with a $95 \%$ confidence interval, was calculated to be adequate and targeted accordingly.

\section{Instrumentation}

A demographic questionnaire was used to survey the characteristics of the sample. The Revised Pain Knowledge and Attitudes Questionnaire (RPKAQ) - which covers a wide base of knowledge that is appropriate for healthcare professionals, including sections on physiological, psychological, developmental, assessment/measurement, pharmacological and cognitive/behavioural aspects of pain knowledge - was adapted for the study. The section on pharmacological management of pain was excluded, as pharmacology is outside the scope of practice of SA physiotherapists.

The content validity of the original Pain Knowledge and Attitudes Questionnaire (PKAQ) was established by consultation with five internationally recognised experts in pain research, and a Cronbach's a of 0.65 was reported. ${ }^{[11]}$ Internal consistency of the adapted RPKAQ used in this study was established post hoc by calculating reliability; it was shown to have an acceptable Cronbach's $\alpha$ of 0.62. As summarised in Table 1, $\alpha$-values were determined for each question and recalculated with individal items deleted to explore the contribution that each item made to the underlying construct of the subscale. The omission of items did not significantly affect the underlying construct of the questionnaire. Four questions caused a slight increase in $\alpha$-value when omitted, suggesting that there may have been an associated interpretation issue. However, as the increase in $\alpha$-value was $<0.1$ in each case, the items were retained.

\section{Procedure}

All members of the SPG and OMPTG were informed of the purpose of the study via e-mail. The e-mail included a link to the questionnaire on Survey Monkey. Electronic informed consent was obtained prior to providing access to the questionnaire. All data were anonymous.

\section{Statistical analysis}

Data were analysed for those who completed the full questionnaire. Respondents who completed only the demographic data or did not complete the full questionnaire were excluded from the analysis. The score selected to represent an appropriate level of knowledge for the RPKAQ was 75\%, as this represents a first-class pass at SA universities. Pain has been identified as the fifth vital sign, ${ }^{[4]}$ indicating the attention with which physiotherapists should be assessing pain. Vital signs are critical; therefore, $75 \%$ was regarded as a necessary score of adequate knowledge if pain is to be assessed as seriously as other vital signs. Correlations between pain knowledge and gender, ethnicity, academic training and clinical experience were analysed. 
The demographic data and knowledge of the whole sample group were presented using descriptive statistics in the form of means \pm standard deviations (SDs). Differences in levels of knowledge between two independent groups, those with adequate $v$. inadequate pain knowledge, were analysed using the Mann-Whitney U-test for numerical data and the $\chi^{2}$ test for categorical data. Relationships between levels of knowledge and factors that may influence knowledge were illustrated using Spearman's correlation coefficients. Significance was accepted at $p<0.05$.

Results

A total of 207 respondents completed the full questionnaire, representing a response rate of $13.25 \%$.

\section{Descriptive characteristics}

The sociodemographic and professional characteristics of the participants are presented in Table 2. The participants were predominantly female, English-speaking, with a mean 14 years of experience as physiotherapists. The majority had experience in treating athletes and had been doing so for a mean of 12 years.

Pain knowledge and attitudes questionnaire The mean RPKAQ score was $66 \%$ (SD \pm 9 ). The lowest scores were obtained for the 'assessment and measurement' (48\%; SD \pm 16 ) and 'developmental' (59\%; SD \pm 21 ) sections of the RPKAQ. The highest scores were obtained for the 'physiology' (77\%; SD \pm 15 ) and 'psychology' (73\%; SD \pm 11$)$ sections. The mean score for the 'cognitive/behavioural' section of the RPKAQ was $68 \%$ (SD \pm 12 ). No significant correlations were found between the total RPKAQ scores and gender, home language, postgraduate qualification or experience in treating athletes.

\section{Adequate pain knowledge scores}

Only $15 \%$ of the participants had adequate scores on the RPKAQ (i.e. score $\geq 75 \%$ ). A comparison of the percentage of participants obtaining adequate scores in each of the RPKAQ subsections is illustrated in Fig. 1. The only subsection in which the majority of participants obtained adequate scores was 'physiology', with $57 \%$ of participants receiving an adequate score ( $\geq 75 \%)$. Only $4 \%$ of the participants had adequate knowledge in the 'assessment and measurement' section.
Table 2. Sociodemographic characteristics of the sample $(N=207)$

\begin{tabular}{|c|c|}
\hline Age (years), mean $( \pm \mathrm{SD})$ (range) & $38( \pm 10)(23-68)$ \\
\hline \multicolumn{2}{|l|}{ Gender, $n(\%)$} \\
\hline Female & $184(89)$ \\
\hline Male & $23(11)$ \\
\hline \multicolumn{2}{|l|}{ Home language, $n$ (\%) } \\
\hline English & $111(54)$ \\
\hline Afrikaans & $79(38)$ \\
\hline English/Afrikaans & $6(3)$ \\
\hline Sesotho & $2(1)$ \\
\hline SiSwati & $1(0.5)$ \\
\hline Xitsonga & $1(0.5)$ \\
\hline Dutch & $1(0.5)$ \\
\hline German & $4(2)$ \\
\hline English/Italian & $1(0.5)$ \\
\hline English/Portuguese & $1(0.5)$ \\
\hline \multicolumn{2}{|l|}{ Postgraduate qualifications, $n(\%)$} \\
\hline Professional postgraduate course & $119(57)$ \\
\hline Masters & $33(16)$ \\
\hline $\mathrm{PhD}$ & $2(9)$ \\
\hline \multicolumn{2}{|l|}{ Currently in clinical practice, $n(\%)$} \\
\hline Yes & $191(92)$ \\
\hline No & $16(8)$ \\
\hline Years of clinical experience, mean $( \pm \mathrm{SD})$ (range) & $15( \pm 10)(1-44)$ \\
\hline \multicolumn{2}{|l|}{ Experience treating athletes, ${ }^{\star} n(\%)$} \\
\hline Yes & $193(93)$ \\
\hline No & $14(7)$ \\
\hline Number of years treating athletes, mean $( \pm S \mathrm{SD})$ (range) & $12( \pm 11)(0-40)$ \\
\hline
\end{tabular}

${ }^{*}$ Athlete is defined as any person who is proficient in sports and/or any other form of exercise, at any level of participation.

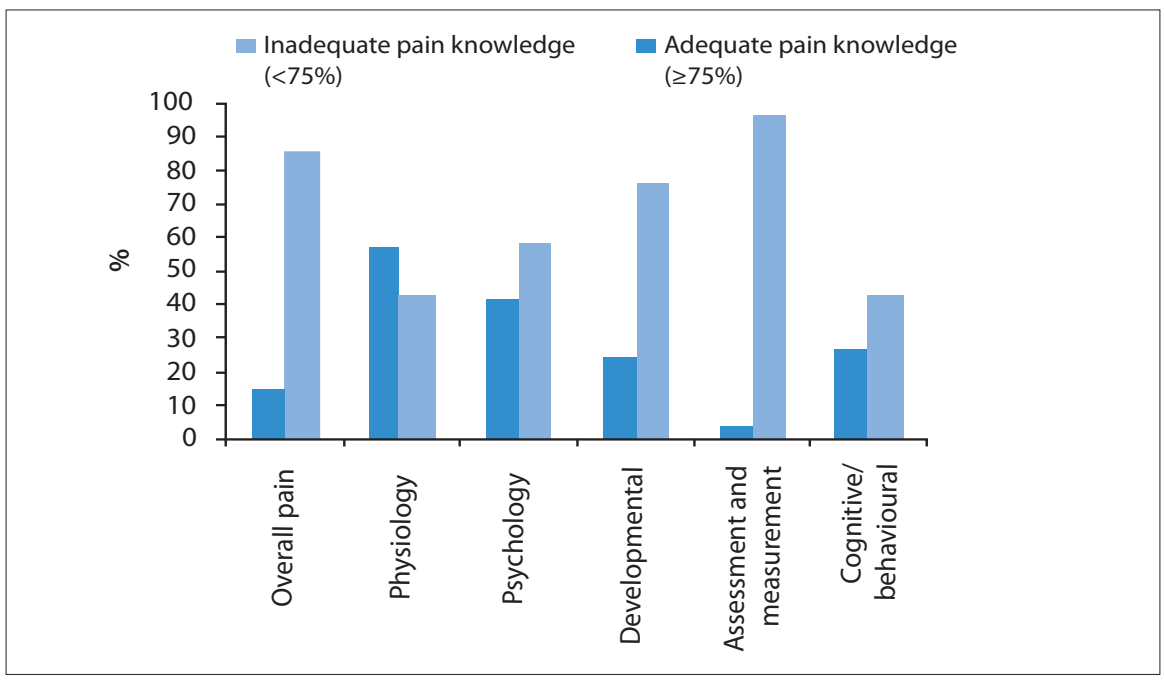

Fig. 1. Percentage of participants obtaining adequate and inadequate scores on the RPKAQ. 


\section{Factors contributing to pain knowledge}

The analysis of variables according to adequate or inadequate pain knowledge (RPKAQ $\geq 75 \%$ ) revealed no differences in terms of gender for the total score or for any of the subsections. There were no significant differences between those with adequate v. inadequate in terms of home language. In addition, there was no difference in the pain knowledge scores between those who completed their undergraduate degree in their home language and those who completed their undergraduate degree in a second language. Those who studied in their first or home language scored significantly higher $(77 \%$; SD \pm 14$)$ in the 'physiology' section of the RPKAQ than those who studied in their second language (68\%; $\mathrm{SD} \pm 15)(\mathrm{U}=677.00 ; p=0.04)$.

Furthermore, no significant differences were found between those with adequate pain knowledge and those with inadequate pain knowledge in terms of years of clinical experience or experience in treating athletes.

There was a weak but significant positive correlation between the number of years since graduation and the 'psychology' section of the RPKAQ $(r=0.20 ; p<0.05)$, as well as the 'cognitive/behavioural' section of the RPKAQ $(r=0.17 ; p<0.05)$. This correlation showed that increased time since graduation corresponded with better knowledge scores for the psychological and cognitive/behavioural aspects of pain.

Similarly, there was a weak positive correlation between the number of years in clinical practice and the pain knowledge scores in the psychological $(r=0.19 ; p<0.05)$ and cognitive/behavioural aspects of pain $(r=0.17 ; p<0.05)$.

Furthermore, physiotherapists who were involved in lecturing scored significantly higher in the 'physiology' section than those who were not ( $84 \%(S D \pm 12)$ v. $75 \%$ ( $S D \pm 15$ ), respectively; $U=2$ 093.50; $p=0.0005$ ). The type of lecturing (undergraduate, postgraduate and/or continued education courses), however, was not significant $\left(\chi^{2}=9.91\right.$; $p=0.13)$.

\section{Discussion}

Physiotherapists have a central role in all aspects of pain assessment and management, particularly in the management of musculoskeletal injuries. The mean score for the RPKAQ in the study sample was $65 \%$. This is well below the score regarded as indicating adequate knowledge $(\geq 75 \%)$. These results are concurrent with a previous SA study which also identified poor pain knowledge scores in final-year health sciences students. ${ }^{[4]}$ The spread of scores across the different knowledge areas in the present study reaffirms the findings of Parker et al..$^{[4]}$ and Strong et al. ${ }^{[11]}$ who identified the areas of most knowledge to be in the physiological aspects of pain, while assessment and measurement knowledge was found to be least understood.

This is one of only a few studies where attempts have been made to quantify adequate pain knowledge, classified as a minimum RPKAQ score of $75 \%$. It is of concern that $86 \%$ of the physiotherapists had inadequate scores on the RPKAQ; thus indicating a poor level of pain knowledge among members of the sports and orthopaedic manipulative physiotherapy groups in SA. The significance of this is highlighted by the fact that poor knowledge of current best evidence about pain may limit efficacy of intervention, ${ }^{[12]}$ leading to poor assessment and management of patients with musculoskeletal pain. ${ }^{[4,9]}$ These factors represent barriers to the reconceptualisation of the problem of chronic pain. ${ }^{[12]}$ Despite IASP guidelines aiming to improve and standardise pain education, there is a paucity of research on the pain curriculum content in healthcare courses in an SA context. The results of the present study indicate the need for improved education in pain, with particular focus on the assessment and measurement' and 'developmental' aspects of pain. It is unclear whether the deficit in pain education lies at an undergraduate or postgraduate level. Considering the results of the present study, where postgraduate qualification was not associated with improved scores, targeting undergraduate training may be most beneficial.

The literature highlights the importance of pain education for accurate pain assessment and management, as well as the correlation between pain education and improved knowledge. ${ }^{[14,15]}$ Well-designed pain curricula can significantly improve pain knowledge and the associated beliefs of health professional students. ${ }^{[14]}$

In this study, academic training made no significant contribution to overall pain knowledge, possibly since the majority of the physiotherapists graduated over 10 years ago. Perhaps adequate education may not be associated directly with effective use of knowledge; which leads one to question the influence of other factors in healthcare professionals' pain-management strategies. Moseley ${ }^{[12]}$ reported that health professionals underestimate their patients' ability to understand the neurophysiology of pain; therefore, it is reasonable to assume that this may not form part of the theoretical basis of treatment or be included in the management approach. ${ }^{[12]}$ Further, clinical reasoning of pain appears to influence reasoning associated with other aspects of clinical practice such as the planning of physical examinations, treatment and prognostication. ${ }^{[10]}$

Previous studies have found that clinical experience influences knowledge of pain. ${ }^{[16,17]}$ However, in the present study there was no significant relationship between overall pain knowledge and clinical experience. Other studies concurrently show no significant correlation between postgraduate years of experience and pain knowledge. ${ }^{[12]}$ Interestingly, in the present study, there was a weak but significantly positive correlation between the number of years since graduation and pain knowledge related to the psychological and cognitive behavioural aspects of pain. This correlation showed that increased time since graduation was positively associated with better knowledge scores. Considering that the pain education curriculum has become more salient in the past decade, one may expect to find the opposite result, i.e. for physiotherapists who trained more recently to have higher scores. This association between experience and better scores may be as a consequence of increased exposure to the psychosocial elements involved in treating athletes and/or patients with chronic pain. Furthermore, perhaps with maturity and clinical experience, physiotherapists acknowledge the relevance of the psychosocial aspects of pain management. In addition, there may be better multidisciplinary interaction between older physiotherapists and psychologists. One could argue that older physiotherapists may be more flexible in accepting a biopsychosocial framework and have a wider understanding of pain beliefs and coping strategies.

\section{Study limitations}

It is recognised that the sample size was insufficient to ensure the $95 \%$ confidence level targeted. A larger sample size may have allowed a better representation of gender, ethnicity, academic training and clinical experience of the SA physiotherapy population, and may have 
influenced the results differently. In addition, uneven distribution of characteristics within the sample may have obscured the outcomes. However, despite the low response rate (13.25\%) and the sample size being smaller than the targeted 272 required for a $95 \%$ confidence level, a sample of 207 gave a $90 \%$ confidence level, which is regarded as acceptable in surveys of the type described here. ${ }^{[16]}$ The participants were all physiotherapists registered to practise in SA with a special interest in sports and/or orthopaedic manipulative physiotherapy. This study provides valuable information on a population group in which there is a paucity of evidence regarding pain knowledge.

Further limitations are found by virtue of the study design. Selfadministered questionnaires are common measurement tools used to assess descriptive characteristics and obtain information from large populations. However, questionnaires are also associated with low response rates. ${ }^{[18]}$ To minimise the limitations of self-administered questionnaires, a pilot study was conducted on the online demographic questionnaire and RPKAQ used in the present study to assess the feasibility, accessibility, comprehension and ease of completion. However, the present study was unable to control for the disadvantages associated with self-administered questionnaires, including accuracy of mailing lists; literacy and language issues (such as dyslexia and translation); interpretation of the questions; and technical problems (possible online faults or limited access to the internet). ${ }^{[19]}$

There may be sample bias in the results due to the differences in motivation between those individuals who chose to respond and those who did not respond. Respondents may not have been motivated to give accurate answers, but rather to give answers that presented themselves in a favourable light. Furthermore, it is identified that people who feel more confident in their knowledge are more likely to respond to questionnaires than those who feel they have insufficient knowledge. ${ }^{[4]}$ If this is the case and physiotherapists with poor knowledge about pain were not motivated to respond, then the results were effectively inflated by a selection bias.

The content validity of the original PKAQ was established by consultation with five internationally recognised experts in pain research. ${ }^{[1]}$ Although the questionnaire was originally utilised over 10 years ago, the questions still hold true today. The adapted RPKAQ had an acceptable Cronbach's $\alpha$ of 0.62 . There is, however, room for revision and improvement, with the objective to develop a more recent and reliable outcome measure for pain knowledge. It is noted that cross-cultural adaptation of the questionnaire for the SA population may enhance applicability of the findings and that test-retest reliability could have been included in the pilot study to strengthen the dependability of the questionnaire.

\section{Conclusion}

Despite its limitations, the present study demonstrated that members of the sports and orthopaedic manipulative physiotherapy groups in SA may have inadequate pain knowledge. Based on a minimum score of $75 \%$, indicating adequate knowledge to assess and treat a vital sign, the physiotherapists in our sample had insufficient knowledge to ensure optimal pain assessment and management. In particular, there was a lack of knowledge in the assessment and measurement of pain as well as in the developmental aspects of pain. There was no significant contribution by academic training, clinical experience, gender or ethnicity to overall pain knowledge. The content of pain education in both undergraduate and postgraduate curricula for physiotherapists should be explored to identify the specific areas of pain education that are lacking, and to optimise the efficacy of pain education for physiotherapists treating athletes in SA.

Acknowledgements. We acknowledge all the physiotherapists who volunteered to participate in the study, and the South African Society of Physiotherapy committee, including Dr Ina Diener (OMPTG NEC Chairperson), Kerryn Milella (SPG Secretary), Ria Sandenbergh (SPG Chairperson), Magda Fourie (consultant physiotherapist) and Lucelle Naidoo (National Operations Manager).

\section{References}

1. IASP Taxonomy. Pain Terms. http://www.iasp-pain.org/AM/Template. cfm?Section=Pain_Definitions (accessed 4 July 2012).

2. Main CJ, Watson PJ. Psychological aspects of pain. Manual Therapy 1999;4(4):203215. [http://dx.doi.org/10.1054/math.1999.0208]

3. Scudds RJ, Scudds RA, Simmonds MJ. Pain in the physical therapy (pt) curriculum: A faculty survey. Physiotherapy Theory and Practice 2001;17(4):239-256. [http://dx.doi. org/10.1080/095939801753385744]

4. Parker R, Gush S, Vale M, et al. Pain knowledge and attitudes in final year health science students at the University of Cape Town. Pain SA 2009;4(2):5-10.

5. Elliot M, Coventry A. Critical care: The eight vital signs of patient monitoring. Br J Nurs 2012;21(10):621-625.

6. Pain as the 5th Vital Sign Toolkit. http://www.va.gov/painmanagement/docs/ TOOLKIT.pdf (accessed 7 July 2011).

7. Brown CA. Treatments for patients with chronic pain: Therapists' beliefs. British Journal of Therapy and Rehabilitation 2003;10(2):46-51.

8. South African Society of Physiotherapy. Position Paper: The First Line Practitioner Status of Physiotherapists. http://www.physiosa.org.za (accessed 27 July 2011).

9. Nijs J, Van Houdenhove B, Oostendorp R, et al. Recognition of central sensitization in patients with musculoskeletal pain: Application of pain neurophysiology in manual therapy practice. Man Ther 2010;15(2):135-141. [http://dx.doi.org/10.1016/j. math.2009.12.001]

10. Smart K, Doody C. The clinical reasoning of pain by experienced musculoskeletal physiotherapists. Man Ther 2007;12(1):40-49. [http://dx.doi.org/10.1016/j. math.2006.02.006]

11. Strong J, Tooth L, Unruh A. Knowledge about pain among newly graduated occupational therapists: Relevance for curriculum development. Can J Occup Ther 1999;66(5):221-228. [http://dx.doi.org/10.1177/000841749906600505]

12. Moseley L. Unravelling the barriers to reconceptualization of the problem in chronic pain: The actual and perceived ability of patients and health professionals to understand the neurophysiology. J Pain 2003;4(4):184-189. [http://dx.doi. org/10.1016/S1526-5900(03)00488-7]

13. Ali N, Thomson D. A comparison of the knowledge of chronic pain and its management between final year physiotherapy and medical students. Eur J Pain 2009;13(1):38-50. [http://dx.doi.org/10.1016/j.ejpain.2008.02.005]

14. Hunter J, Watt-Watson J, McGillion M, et al. An interfaculty pain curriculum: Lessons learned from six years experience. Pain 2008;140(1):74-86. [http://dx.doi. org/10.1016/j.pain.2008.07.010]

15. Moseley GL. Evidence for a direct relationship between cognitive and physical change during an education intervention in people with chronic low back pain. Eur J Pain 2004;8(1):39-45. [http://dx.doi.org/10.1016/S1090-3801(03)00063-6]

16. Enskar K, Ljusegren G, Berglund G, et al. Attitudes to and knowledge about pain and pain management of nurses working with children with cancer: A comparative study between UK, South Africa and Sweden. J Res Nurs 2007;12(5):501-515. [http://dx.doi. org/10.1177/1744987107080455]

17. Wilson B. Nurses' knowledge of pain. J Clin Nurs 2007;16(6):1012-1020. [http:// dx.doi.org/10.1111/j.1365-2702.2007.01692.x]

18. Kelley K, Clark B, Brown V, et al. Methodology matters. Good practice in the conduct and reporting of survey research. Int J Qual Healh Care 2003;15(3):261-266.

19. Bourque L, Fielder E. The Survey Kit: How to Conduct Self-Administered and Mail Surveys. 2nd ed. Washington: Sage Publications, 2003. 